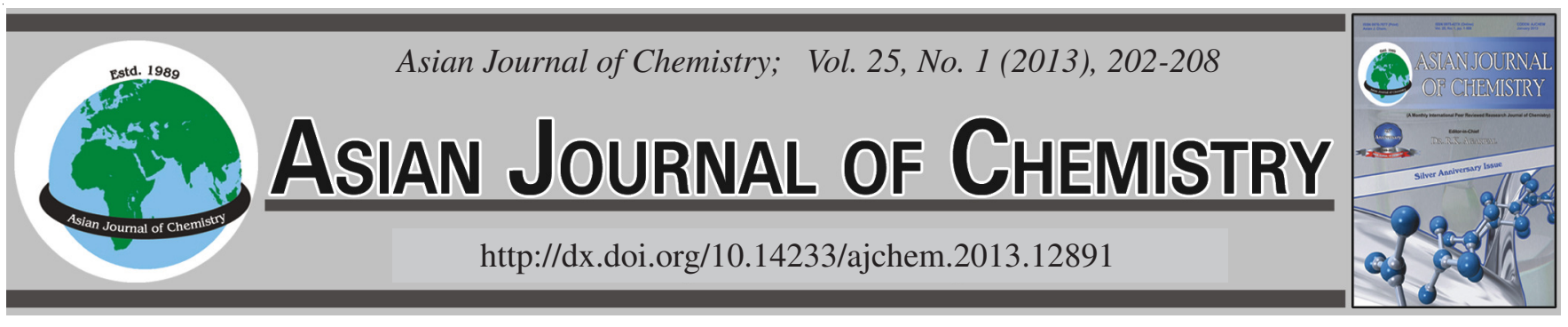

\title{
Response Surface Design for the Optimization of the Removal of Chlorella pyrenoidosa Low Frequency Ultrasonic Irradiation
}

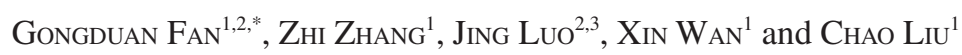

${ }^{1}$ Key Laboratory of the Three Gorges Reservoir Region's, Eco-environment under the State Ministry of Education, Chongqing University, Chongqing 400045, P.R. China

${ }^{2}$ College of Civil Engineering, Fuzhou University, Fuzhou 350108, Fujian Province, P.R. China

${ }^{3}$ People's Liberation Army Logistics Engineering College, Environmental Protections Scientific Institute, Chongqing 400016, P.R. China

*Corresponding author: Fax: +86 23 65120811; Tel: +86 23 65127191; E-mail: cqufgd@126.com; fgd@cqu.edu.cn

\begin{abstract}
Water blooms caused by blue and greet cyanobacteria has been shown to be hazardous to both animals and humans. Ultrasonic algae removal technology can be good for controlling algae growth by appropriate power, frequency and irradiation time. First of all, the approximate ranges of the ultrasonic parameters, frequency, power and irradiation time, were estimated with single factor experiments. Then the optimized values of the three parameters were determined by central composite design of response surface design. Results showed that the removal rate of chlorophyll-a reached to $64.1 \%$ after the irradiation for 7 min by ultrasonic of $77 \mathrm{kHz}$ and $100 \mathrm{~W}$. Ultrasonic technology can remove Chlorella pyrenoidosa in water quickly and effectively, so as to achieve the purpose of water purification.
\end{abstract}

Key Words: Ultrasonic irradiation, Algae removal, Chlorella pyrenoidosa, Response surface design.

ᄂ - - - - - - - - - - - - - - - - - - - - - - - - - -

\section{INTRODUCTION}

With the development of the social industrialization, a large number of pollutants containing nitrogen, phosphorus have been let out into water, greatly accelerating the process of eutrophication of natural waters, resulting in overgrowth of algae in the water and the water bloom outbreaks more and more frequently. Because of the water bloom caused by the blue and green algae, the water became foul and the algal toxins appeared. At present there are many ways to control the algae in water. Such as control the pollution load, add algaecide, artificial aeration mixing, clay or activated carbon adsorption and biological methods. For the waterworks, the commonly used unit processes are chemical methods, biological flotation and direct filtration treatment ${ }^{1,2}$. But due to technical limitations of the various methods, in terms of safety, affordability and efficiency of algae removal does not meet the requirements. The removal of algae by ultrasonic, which is clean and efficient, referred to as environment-friendly technologies ${ }^{1,3,4}$, has advantages of moderate operation conditions. It can be used alone or in combination with other water treatment technology. Previous studies have shown that the control parameters such as ultrasonic frequency, ultrasonic power and ultrasonic irradiation time have a significant impact on effectiveness of the removal of algae and energy consumption. The selection of control parameter is critical. At present, the number of species of green algae and blue algae is the most in Phytoplankton community structure in fresh water. Green algae is the dominant algae in some areas ${ }^{5,6}$. Chlorella pyrenoidosa is the typical type of green algae, which is common and easy to leading to algal bloom. Study on removal and inhibition of microcystis cyanobacteria, spirulina and other algae using ultrasonic technique has been more focused ${ }^{1,2,4,7,8}$, however, research on Chlorella pyrenoidosa is still relatively little.

Response surface method for the design is an analysis method of test condition optimization with a combination of mathematics and statistics. It considers both test random error and complex relationship between unknown function fitted with multiple regression equations within the small area, which is a valid method used to optimize production conditions, reduce costs, improve product quality and solve actual problems in the production ${ }^{9}$. In this article, ultrasonic frequency, power and irradiation time are used as control parameters to study the influence of ultrasonic removal of Chlorella pyrenoidosa for selecting a suitable scope for further testing; and then central composite design and response surface is used to analyze the best values of control parameters, for providing theoretical basis of the ultrasonic control of Chlorella pyrenoidosa blooms in water. 


\section{EXPERIMENTAL}

Experimental apparatus of ultrasonic: ATANA AT3020 signal generator is used as ultrasonic signal source. Power amplifier is predicted by the Buddha in Nanjing technology industrial production, model HFVA-62. Ultrasonic transducer for reactor is ultrasonic horn launch, developed by the Institute of acoustics, Chinese Academy of Sciences. The rest reactor is self-made, ultrasonic apparatus show as Fig. 1.

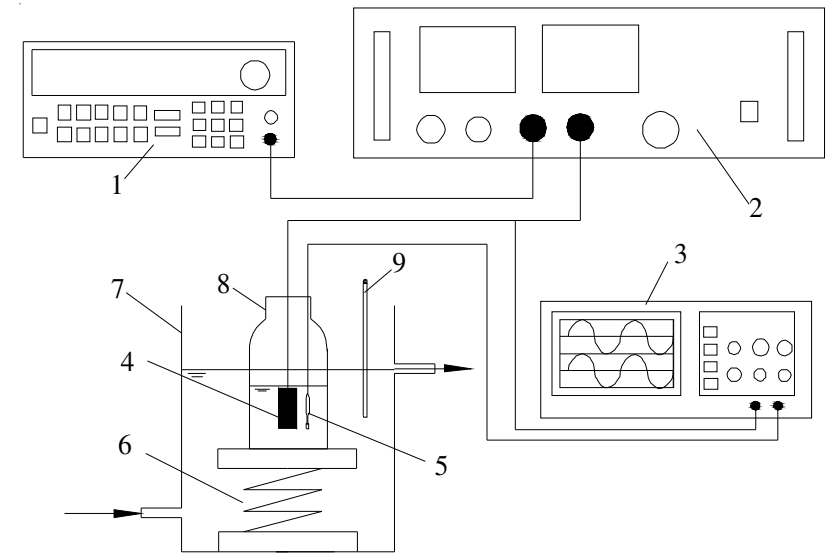

Fig. 1. Experimental apparatus of ultrasonic (1. Signal Generator; 2. Power Amplifier; 3. Oscilloscope; 4. Transducer, 5. Hydrophone; 6. Telescopic stand; 7. Cooling; 8. Glass flask; 9. Thermometer)

Determination of experimental parameters: Detection of ultrasonic frequency and power use the Ut2025C oscilloscope produced by unit-trend group limited in Hong Kong and CS-3A hydrophone developed by the Institute of acoustics, Chinese Academy of Sciences. Aqua fluor handheld chlorophyll fluorescence tester was used to detect Chlorophyll-a, which was developed by United States Turner Designs, model 8000-010.

Algae species and culture methods: Chlorella pyrenoidosa was provided by fresh water algae culture collection of the Institute of Hydrobiology of Chinese Academy of Sciences (FACHB-9). SE medium, medium formulations: $0.25 \mathrm{~g} / \mathrm{L}$ $\mathrm{NaNO}_{3}, 0.075 \mathrm{~g} / \mathrm{L} \mathrm{K}_{2} \mathrm{HPO}_{4} .3 \mathrm{H}_{2} \mathrm{O}, 0.075 \mathrm{~g} / \mathrm{L} \mathrm{MgSO} 4.7 \mathrm{H}_{2} \mathrm{O}$, $0.025 \mathrm{~g} / \mathrm{L} \mathrm{CaCl} 2.2 \mathrm{H}_{2} \mathrm{O}, 0.175 \mathrm{~g} / \mathrm{L} \mathrm{KH}_{2} \mathrm{PO}_{4}, 0.025 \mathrm{~g} / \mathrm{L} \mathrm{NaCl}$, $0.005 \mathrm{~g} / \mathrm{L} \mathrm{FeCl}_{3} \cdot 6 \mathrm{H}_{2} \mathrm{O} .1 \mathrm{~mL} / \mathrm{L} \mathrm{Fe}-\mathrm{EDTA}, 1 \mathrm{~mL} / \mathrm{L} \mathrm{A}_{5}, 40 \mathrm{~mL} / \mathrm{L}$ soil extract. In which, the solution formula of $\mathrm{A}_{5}$ is: $2.86 \mathrm{~g} / \mathrm{L}$ $\mathrm{H}_{3} \mathrm{BO}_{3}, \mathrm{MnCl}_{2} .4 \mathrm{H}_{2} \mathrm{O} 1.81 \mathrm{~g} / \mathrm{L}, \mathrm{ZnSO}_{4} .7 \mathrm{H}_{2} \mathrm{O} 220 \mathrm{mg} / \mathrm{L}$, $\mathrm{CuSO}_{4} .5 \mathrm{H}_{2} \mathrm{O} 79 \mathrm{mg} / \mathrm{L},\left(\mathrm{NH}_{4}\right)_{6} \mathrm{Mo}_{7} \mathrm{O}_{24} .4 \mathrm{H}_{2} \mathrm{O} 39 \mathrm{mg} / \mathrm{L}$. The solution formula of Fe-EDTA is $\mathrm{Na}_{2}$ EDTA10 g/L, $\mathrm{FeCl}_{3} \cdot 6 \mathrm{H}_{2} \mathrm{O}$ $810 \mathrm{mg} / \mathrm{L}$. The solution formula of soil extract $(1 \mathrm{~L})$ is using a beaker or flask to take garden soil $0.5 \mathrm{~kg}$ without fertilization, adding distilled water $1000 \mathrm{~mL}$. Sealing the beaker or flask with a breathable stopper, heating in a boiling water bath for $2 \mathrm{~h}$, then cooling it for several hours. Filter under sterile conditions. Then take the supernatant, add sterile distilled water to the total volume of $1000 \mathrm{~mL}$. Soil extract stored in $4{ }^{\circ} \mathrm{C}$ for use. Algae-laden liquid initially placed in the $500 \mathrm{~mL}$ triangle flask, put in light training incubator at $25^{\circ} \mathrm{C}, 2000$ lux and keep ventilation and appropriate daily mixing. Later, expand in $20 \mathrm{~L}$ glass fish tank. Aerate 3 times every day. In this experiment, the algae we choose is in Logarithmic phase, it is that the algae density reached at $10^{7}$ cells $/ \mathrm{mL}$.
Experimental methods: $800 \mathrm{~mL}$ algae fluid was put respectively into a group of $1 \mathrm{~L}$ beakers. Put the ultrasonic transducer $30 \mathrm{~mm}$ below the liquid. Irradiate the algae solution using different frequency, power and irradiation time. And then, determine the chlorophyll-a concentration in supernatant and calculated the chlorophyll-a removal rate, which is used as assessment index. The expressions is shown as eqn. (1).

$$
\text { Removal of chlorophyll }-\mathrm{a}=\frac{\text { Chla }_{0}-\mathrm{Chla}_{1}}{\text { Chla }_{0}} \times 100 \%
$$

where, $\mathrm{Chla}_{0}$ is the Chlorophyll-a concentration of Chlorella pyrenoidosa before ultrasonic treatment, $\mu \mathrm{g} / \mathrm{L}, \mathrm{Chla}_{1}$ is Chlorophyll-a concentration of Chlorella pyrenoidosa after ultrasonic treatment, $\mu \mathrm{g} / \mathrm{L}$.

\section{RESULTS AND DISCUSSION}

\section{Single-factor experiments}

Experiment of different ultrasonic frequency: With 80 W ultrasonic, algae liquid was irradiated by frequency 20,40 , $80,100,120$ and $150 \mathrm{kHz}$ for $5 \mathrm{~min}$ for the research on removal effective of different ultrasonic frequency. The results were shown in Fig. 2.

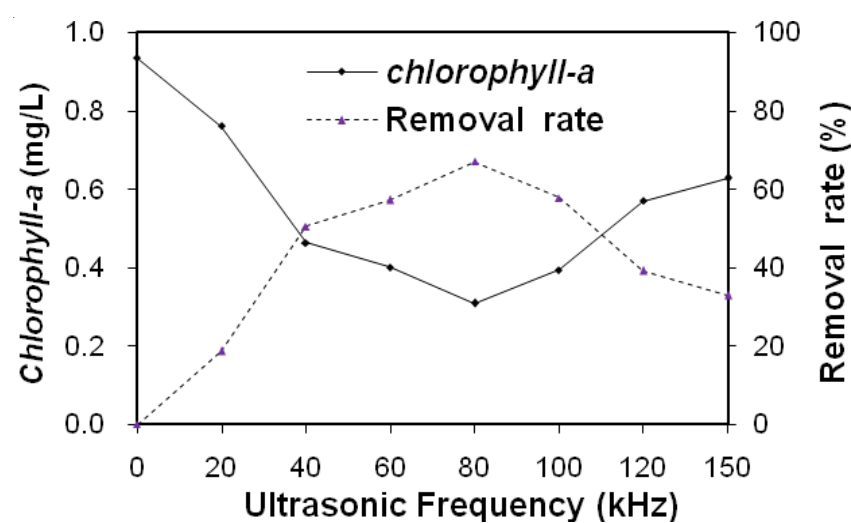

Fig. 2. Effect of ultrasonic frequency on removal of chlorophyll-a of Chlorella pyrenoidosa

From Fig. 2, it is clear that under the condition with power of $80 \mathrm{~W}$ and irradiation time of $5 \mathrm{~min}$, for different frequencies, the content chlorophyll will lower with the increasing of ultrasonic frequency at first. It is that the removal rate increase with the increasing of ultrasonic frequency. When the frequency is $80 \mathrm{kHz}$, the immediate removal rate will reach to $62.35 \%$. When the frequency is greater than $80 \mathrm{kHz}$, the removal rate of chlorophyll will decrease with the increasing of ultrasonic frequency. When frequency is $80 \mathrm{kHz}$, the immediate removal rate will be the maximum. With the frequency continues increasing; the immediate removal rate will have a trend of decrease. So the removal effect will be the best when the frequency is at $40 \mathrm{kHz}-100 \mathrm{kHz}$. The removal rate will be the maximum when the frequency is about 80 $\mathrm{kHz}$. At this time, the removal rate of chlorophyll- $a$ can reach to $62.35 \%$. Existing researches generally believe that cavitation is the main reason for the removal of algae cells ${ }^{2,4}$. Biological tissue and tissue fluids contain many tiny air bubbles. Expansion, contraction, vibration, crashes and other cavitation process are generated on micro-bubbles when ultrasonic irradiates, 
resulting in the sound hole effect ${ }^{10}$. Algal cells at the velocity wave nodes in the standing wave would continue colliding with large particles and accumulate, leading to death or deposition. When the ultrasonic frequency super closes to the resonant frequency of algal cells, the damage of algal cells would be more obvious and the removal of algal cells would be more effective $\mathrm{e}^{10,11}$. When the ultrasonic with the frequency of $\mathrm{f}_{0}$ generates cavitation, harmonics with the frequency of $2 \mathrm{f}_{0}, 3 \mathrm{f}_{0}$, etc. will be produced. The higher the ultrasonic frequency is, the closer between harmonic frequencies and resonant frequency of algal cells are. However, the excessive frequency makes cavitation difficult to generate, leading to decrease of cavitation intensity ${ }^{10}$. Therefore, the combined effects of these reasons lead to the removal rate of chlorophyll$a$ increasing first and then decreasing (Fig. 2).

Experiment of different ultrasonic frequency: With $80 \mathrm{kHz}$ ultrasonic, algae liquid was irradiated by different power for 5 min for investigating the removal efficiency with ultrasonic power $20,40,60,80,100,120$ and $140 \mathrm{~W}$. The results are shown in Fig. 3.

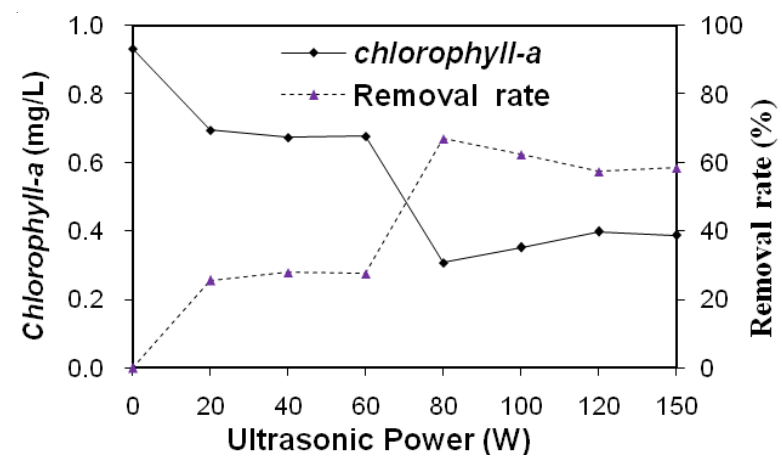

Fig. 3. Effect of ultrasonic power on removal of chlorophyll-a of Chlorella pyrenoidosa

Fig. 3 showed that when the ultrasonic power is at 0-60 $\mathrm{W}$, the greater the power is, the slower the increasing rate of removal rate of algal cells is. When the power is $60 \mathrm{~W}$, there comes a trough. And when the power is at $60-80 \mathrm{~W}$, the removal rate will increase sharply. The removal rate is $62.35 \%$ when the power is $60 \mathrm{~W}$. When the ultrasonic power is at 80 $140 \mathrm{~W}$, with the ultrasonic power increasing, the removal rate of Chlorella pyrenoidosa increase slowly, almost remains unchanged. The main reason is that, there is driving sound pressure during the process of cavitation bubbles' movement. The higher excitation sound pressure increases, the more obvious the shock effect is ${ }^{3}$. When ultrasonic frequency and the initial radius are in certain circumstances, the larger excitation sound pressure is, the stronger the degree of bubble collapse is, so is cavitation ${ }^{6}$. Therefore, the higher the ultrasonic power, chlorophyll-a removal rate increases gradually when the ultrasonic power rises. At the same time, high sound pressure makes bubbles difficult to collapse ${ }^{6}$, therefore, the rise of chlorophyll-a removal rate tend to slow.

Experiment of different ultrasonic irradiation time: With $80 \mathrm{kHz}, 200 \mathrm{~W}$ ultrasonic, algae liquid was irradiated for different periods of time for the research on removal effective of different ultrasonic irradiation time $(1,5,10,20$ and $30 \mathrm{~min}$ ). The results are shown in Fig. 4.

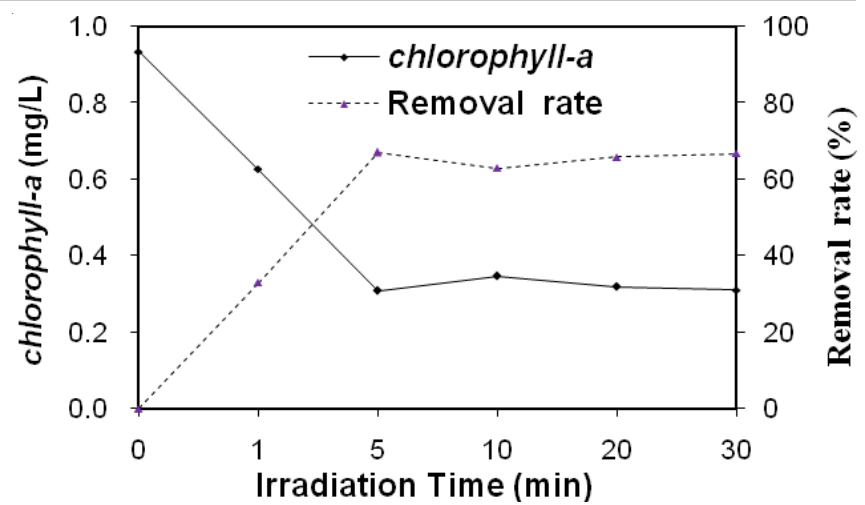

Fig. 4. Effect of ultrasonic irradiation time on removal of chlorophyll-a of Chlorella pyrenoidosa

Fig. 4 showed that under the condition with frequency of $80 \mathrm{kHz}$ and power of $80 \mathrm{~W}$, the removal rate of chlorophyll increased with the time in the first $5 \mathrm{~min}$. After $5 \mathrm{~min}$, there's no obviously increase of removal rate. This showed that ultrasonic's damage to algae cells is mainly happened within the first $5 \mathrm{~min}$. Therefore, the effective time range of algae removing can be $3 \mathrm{~min}$ to $7 \mathrm{~min}$. The result is similar to the ultrasonic removal of Microcystis aeruginosa ${ }^{11}$, because of the related diameter of Chlorella pyrenoidosa and Microcystis aeruginosa.

Optimized experiment conditions: According to the removal effect above and the energy consumption, the optimized ultrasonic frequency level range of response surface experiment of removal Chlorella pyrenoidosa by ultrasonic irradiation is $40 \mathrm{kHz}$ to $100 \mathrm{kHz}$. The ultrasonic power range is $60 \mathrm{~W}-100 \mathrm{~W}$ and the irradiation time range is $3 \mathrm{~min}$ to $7 \mathrm{~min}$.

\section{Response surface analysis}

Response surface design: Based on the design principles of response surface method, the beaker experiment of Chlorella pyrenoidosa removal by ultrasonic irradiation is designed by using the statistical software named Design Expert 7.0 and central composite design model. Factors and levels design is shown in Table-1. Where X1, X2, X3 respectively are ultrasonic frequency $(\mathrm{kHz})$, ultrasonic power $(\mathrm{W})$ and ultrasonic irradiation time ( $\mathrm{min})$. Choose $\mathrm{Y}$, the removal rate of chlorophyll-a (\%), as the assessment indicators. Combined experimental design factors and the results are shown in Table-2.

\begin{tabular}{lccccc}
\multicolumn{7}{c}{ TABLE-1 } \\
FACTORS AND LEVELS OF DESIGN \\
\hline Factor & Variable & Units & Level \\
\hline Ultrasonic frequency & $\mathrm{X}_{1}$ & $\mathrm{kHz}$ & 40.00 & 70.00 & 100.00 \\
Ultrasonic power & $\mathrm{X}_{2}$ & $\mathrm{~W}$ & 60.00 & 80.00 & 100.00 \\
Irradiation time & $\mathrm{X}_{3}$ & $\mathrm{~min}$ & 3.00 & 5.00 & 7.00 \\
\hline
\end{tabular}

The results of the model adaptability analysis and multiple model analysis are shown in Table-3. The analysis result of lack of fit is shown in Table-4. And the comprehensive analysis of $\mathrm{R}^{2}$ is in Table-5.

These indicate that, the second-order model can adapt the response significantly, while the third-order model is aliasing. As can be seen by the Table-3, the model test results should be the second-order model. In which, Prob > F value is less 
than 0.0001. It is to say, comparing with the 2 FI model, there is a comparability not more than $0.01 \%$ for which is more suitable for the forecast of the removal rate of chlorophyll-a. Because of the aliasing, the third-order model will not be considered.

TABLE-2

CENTRAL COMPOSITE DESIGN TEST SCHEME AND RESULTS

\begin{tabular}{ccccc|ccccc}
\hline \multirow{2}{*}{ No. } & \multicolumn{3}{c}{ Factors } & Res. & \multirow{2}{*}{ No. } & \multicolumn{3}{c}{ Factors } & Res. \\
\cline { 2 - 4 } \cline { 7 - 9 } & $\mathrm{X}_{1}$ & $\mathrm{X}_{2}$ & $\mathrm{X}_{3}$ & $\mathrm{Y}$ & & $\mathrm{X}_{1}$ & $\mathrm{X}_{2}$ & $\mathrm{X}_{3}$ & $\mathrm{Y}$ \\
\hline 1 & 40 & 60 & 3 & 26.17 & 11 & 70 & 60 & 5 & 48.84 \\
2 & 100 & 60 & 3 & 33.68 & 12 & 70 & 100 & 5 & 63.92 \\
3 & 40 & 100 & 3 & 48.10 & 13 & 70 & 80 & 3 & 49.15 \\
4 & 100 & 100 & 3 & 43.33 & 14 & 70 & 80 & 7 & 61.45 \\
5 & 40 & 60 & 7 & 28.45 & 15 & 70 & 80 & 5 & 60.10 \\
6 & 100 & 60 & 7 & 40.50 & 16 & 70 & 80 & 5 & 58.60 \\
7 & 40 & 100 & 7 & 46.53 & 17 & 70 & 80 & 5 & 59.85 \\
8 & 100 & 100 & 7 & 64.60 & 18 & 70 & 80 & 5 & 56.75 \\
9 & 40 & 80 & 5 & 49.79 & 19 & 70 & 80 & 5 & 60.13 \\
10 & 100 & 80 & 5 & 51.07 & 20 & 70 & 80 & 5 & 59.50 \\
\hline
\end{tabular}

For the lack of fit, in terms of model, the bigger the Prob $>$ F value is, the better. From Table- 4 we can see that, the Prob $>\mathrm{F}$ value is greater than 0.0001 both in second-order model and third-order model. So, both of these two models can adapt the simulation model. But, because of the aliasing in thirdorder model, it will not be considered. Therefore, based on the analysis of lack of fit, the second-order model has a better adaptability.

According to the $\mathrm{R}^{2}$ comprehensive analysis, the residual sum of squares which predicted by second-order model is the minimum. So it should be selected to model.

Thus, the second-order model is more suitable to be the mathematical model of the removal rate of chlorophyll-a.
Therefore, the second-order model is chosen as the response regression model of chlorophyll-a to find the optimal response factor levels.

Use ultrasonic frequency $\left(\mathrm{X}_{1}\right)$, ultrasonic power $\left(\mathrm{X}_{2}\right)$ and irradiation time $\left(\mathrm{X}_{3}\right)$ as the independent variables and removal rate of chlorophyll-a (Y) as response value to establish the quadratic regression model, showed as eqn. (2):

$$
\begin{gathered}
\mathrm{Y}=-108.329+1.425 \mathrm{X}_{1}+1.826 \mathrm{X}_{2}+7.213 \mathrm{X}_{3}+1.304 \\
\times 10^{-3} \mathrm{X}_{1} \mathrm{X}_{2}+0.057 \mathrm{X}_{1} \mathrm{X}_{3}+0.033 \mathrm{X}_{2} \mathrm{X}_{3}-0.011 \mathrm{X}_{1}^{2}-9.101 \\
\times 10^{-3} \mathrm{X}_{2}^{2}-1.180 \mathrm{X}_{3}^{2}
\end{gathered}
$$

Make an analysis of variance for the model, to ensure the model can reflect the real surface and ensure it can reflect and predict the Chlorella pyrenoidosa removal effect of the ultrasound accurately. Analysis of variance results are in Table-6. Reliability analysis results of model are in Table-7.

Table-7 shows that $\mathrm{R}^{2}=0.9651$ and standard deviation $=$ 2.95 , indicating that regression equation can simulate the real surface. Adeq accuracy is used to measure the signal to noise ratio of a model. When this ratio is greater than 4 , the model can be considered reliable. According to the reliability analysis of the model, the value of Adeq accuracy of this model is 17.696, indicating that the model is reliable and has enough signal to respond the design. It further indicated that, this model can make optimization analysis of the ultrasound parameters when the ultrasound is used to remove Chlorella pyrenoidosa.

Response surface analysis of removal rate of chlorophyll-a: The effect of ultrasound frequency and ultrasound power to the removal rate of chlorophyll- $a$ and the interaction between the two factors are shown in Fig. 5.

Fig. 5 shows that, in the experiment that use ultrasonic to remove Chlorella pyrenoidosa, the removal rate of chlorophyll$a$ increased at first, decreased after with the increasing of the

\begin{tabular}{lcccccc}
\multicolumn{7}{c}{ TABLE -3 } \\
SEQUENTIAL MODEL SUM OF SQUARES FOR CENTRAL COMPOSITE DESIGN \\
\hline Source & Sum of Squares & $\mathrm{df}$ & Mean Square & F-value & $p$-Value Prob $>$ F & Notes \\
\hline Mean $v s$ Total & 51056.52 & 1 & 51056.52 & & & \\
Linear $v$ Mean & 1074.73 & 3 & 358.24 & 4.03 & 0.0259 & \\
2FI $v$ Linear & 112.65 & 3 & 37.55 & 0.37 & 0.7739 & Suggested \\
Quadratic $v s$ 2FI & 1221.78 & 3 & 407.26 & 46.80 & 0.0001 & Aliased \\
Cubic $v s$ Quadra & 76.02 & 4 & 19.00 & & & \\
Residual & 11.01 & 6 & 1.83 & & & \\
\hline Total & 53552.71 & 20 & 2677.64 & & \\
\hline
\end{tabular}

TABLE-4

LACK OF FIT TESTS FOR CENTRAL COMPOSITE DESIGN

\begin{tabular}{lcccccc}
\hline Source & Sum of squares & df & Mean Square & F-value & $p$-value Prob1 $>$ F & Notes \\
\hline Linear & 1412.92 & 11 & 128.45 & 75.22 & $<0.0001$ & \\
2FI & 1300.27 & 8 & 162.53 & 95.19 & $<0.0001$ & \\
Quadratic & 78.49 & 5 & 15.70 & 9.19 & 0.0147 & Suggested \\
Cubic & 2.47 & 1 & 2.47 & 1.45 & 0.2828 & Aliased \\
Pure error & 8.54 & 5 & 1.71 & & & \\
\hline
\end{tabular}

TABLE -5

MODEL SUMMARY STATISTICS FOR CENTRAL COMPOSITE DESIGN

\begin{tabular}{lccccc}
\hline Source & Std. dev. & $\mathrm{R}^{2}$ & Adjusted R & Predicted R & Press \\
\hline Linear & 9.43 & 0.4305 & 0.3238 & -0.0625 & 2652.14 \\
2FI & 10.03 & 0.4757 & 0.2337 & -3.0521 & 10114.90 \\
Quadratic & 2.95 & 0.9651 & 0.9338 & 0.4932 & 1265.11 \\
Cubic & 1.35 & 0.9956 & 0.9860 & -0.2211 & Suggested \\
\hline
\end{tabular}


TABLE-6

ANALYSIS OF VARIANCE OF THE REGRESSION EQUATION

\begin{tabular}{lcccccl}
\hline Source & Sum of squares & df & Mean Square & F- value & p-value Prob $>$ F & Note \\
\hline Model & 2409.16 & 9 & 267.68 & 30.76 & $<0.0001$ & Significant \\
$\mathrm{X}_{1}$ & 116.55 & 1 & 116.55 & 13.39 & 0.0044 & Significant \\
$\mathrm{X}_{2}$ & 789.25 & 1 & 789.25 & 90.69 & $<0.0001$ & Significant \\
$\mathrm{X}_{3}$ & 168.92 & 1 & 168.92 & 19.41 & 0.0013 & Significant \\
$\mathrm{X}_{1} \mathrm{X}_{2}$ & 4.90 & 1 & 4.90 & 0.56 & 0.4704 & Not significant \\
$\mathrm{X}_{1} \mathrm{X}_{3}$ & 93.71 & 1 & 93.71 & 10.77 & 0.0083 & Significant \\
$\mathrm{X}_{2} \mathrm{X}_{3}$ & 14.05 & 1 & 14.05 & 1.61 & 0.2327 & Not significant \\
$\mathrm{X}_{1}^{2}$ & 252.94 & 1 & 252.94 & 29.06 & 0.0003 & Significant \\
$\mathrm{X}_{2}^{2}$ & 36.45 & 1 & 36.45 & 4.19 & 0.0679 & Not significant \\
$\mathrm{X}_{3}^{2}$ & 61.28 & 1 & 61.28 & 7.04 & 0.0242 & Significant \\
Residual & 87.03 & 10 & 8.70 & & & Significant \\
Lack of Fit & 78.49 & 5 & 15.70 & 9.19 & 0.0147 & \\
Pure error & 8.54 & 5 & 1.71 & & & \\
Cor total & 2496.19 & 19 & & & & \\
\hline
\end{tabular}

TABLE - 7

\begin{tabular}{ccccccccc}
\multicolumn{10}{c}{ TABLE -7} \\
MODEL RELIABILITY ANALYSIS \\
\hline Index & Std. dev. & Mean & C.V. $(\%)$ & Press & $\mathrm{R}^{2}$ & Adj. $^{2}$ & Pred. $^{2}$ & Adeq precision \\
\hline Results & 2.95 & 50.53 & 5.84 & 1265.11 & 0.9651 & 0.9338 & 0.4932 & 17.696
\end{tabular}
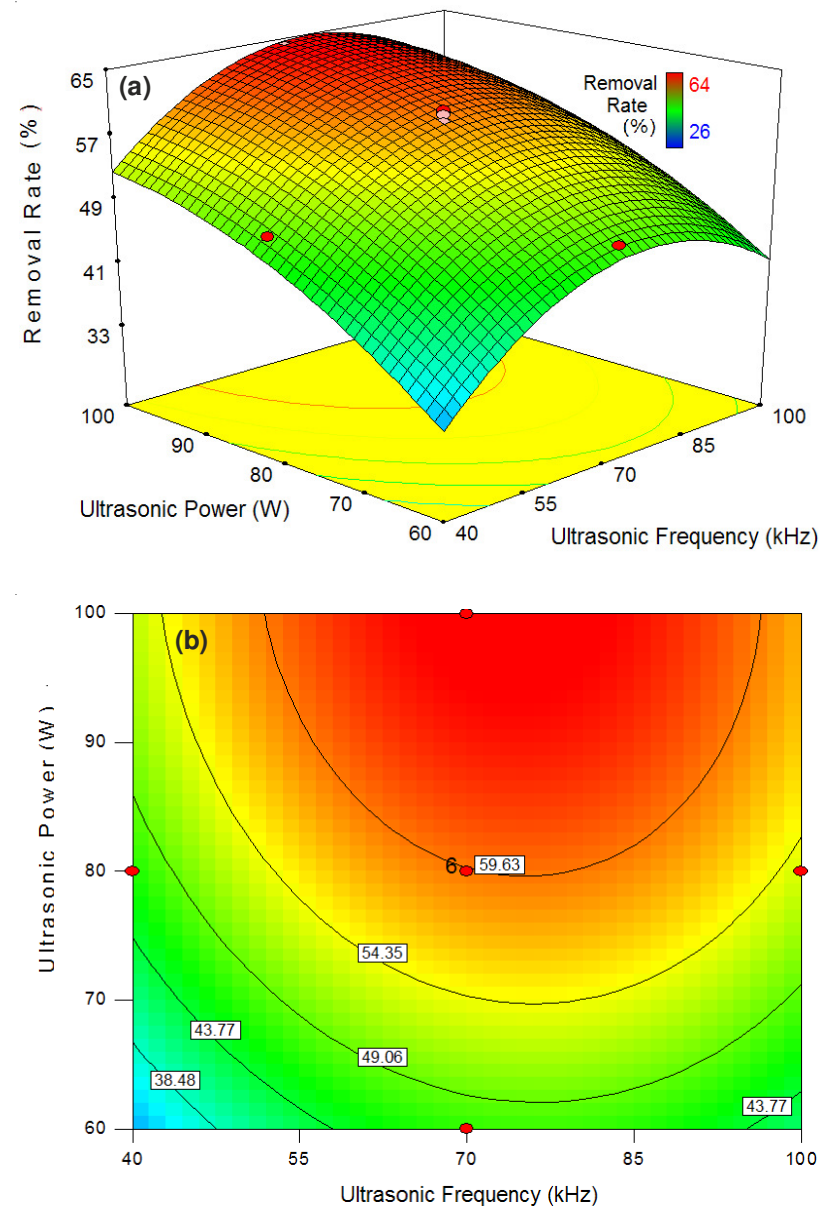

Fig. 5. Interactive effect of ultrasound frequency and power (a) 3D surface (b) $2 \mathrm{D}$

ultrasonic frequency in the detection area. According to the calculated optimum experimental parameters, the optimum frequency is $77 \mathrm{kHz}$. That is keep the ultrasonic power and ultrasonic time invariant, when the frequency is $77 \mathrm{kHz}$, the removal rate of chlorophyll- $a$ is the maximum. While in the single-factor factorial experiment, when the frequency is 80
$\mathrm{kHz}$, the rate of chlorophyll- $\mathrm{a}$ is the maximum. In comparison, there has a small shift in frequency. This may be due to the interaction effect of ultrasonic power. Otherwise, because of the wide interval of the single-factor factorial experimental values, the frequency which corresponding to the maximum value of removal rate may not been taken.

It is also found that, with the ultrasonic power increases, the removal rate of chlorophyll-a is also increasing, but the increasing trend has been observed. It can be expected that, when the ultrasonic power increased to a certain extent, a limit value of removal rate, which indicate that the rate cannot increase significantly even the ultrasonic power continued increasing. According to the selected range of ultrasonic power, when the ultrasonic power is the maximum, $100 \mathrm{~W}$, the removal rate of chlorophyll-a also reached the maximum. When the power increased, the input energy of the algae fluid increased, also the power density of the algae fluid. However, with the input energy of the algae fluid increasing, the cavitation bubbles became difficult to break, which slowed the increasing trend of the removal rate of chlorophyll-a. It is identical to the results of single-factor factorial experiment.

The interaction between ultrasound frequency and ultrasound power manifested in that, when the ultrasound frequency is close to the optimal experimental conditions, that is $77 \mathrm{kHz}$, with the ultrasonic power increasing, the removal rate of chlorophyll-a reached to the limit value and this value is closer to the best removal rate. Because of the interaction, there is an optimal area of the removal rate of chlorophyll- $a$, which is the semi-elliptical area shown in the Fig.5, where the frequency is about $50 \mathrm{kHz}$ to $100 \mathrm{kHz}$ and power is about $80 \mathrm{~W}$ to 100 W. In this area, the removal rate is more than $60.86 \%$.

The effect of ultrasound frequency and irradiation time to the removal rate of chlorophyll- $a$ and the interaction between the two factors are shown in Fig. 6.

Fig. 6 shows that, in the experiment that use ultrasonic to remove Chlorella pyrenoidosa, with the increasing of the ultrasonic frequency in the detection area, the removal rate of chlorophyll- $a$ increased at first, then decreased. 

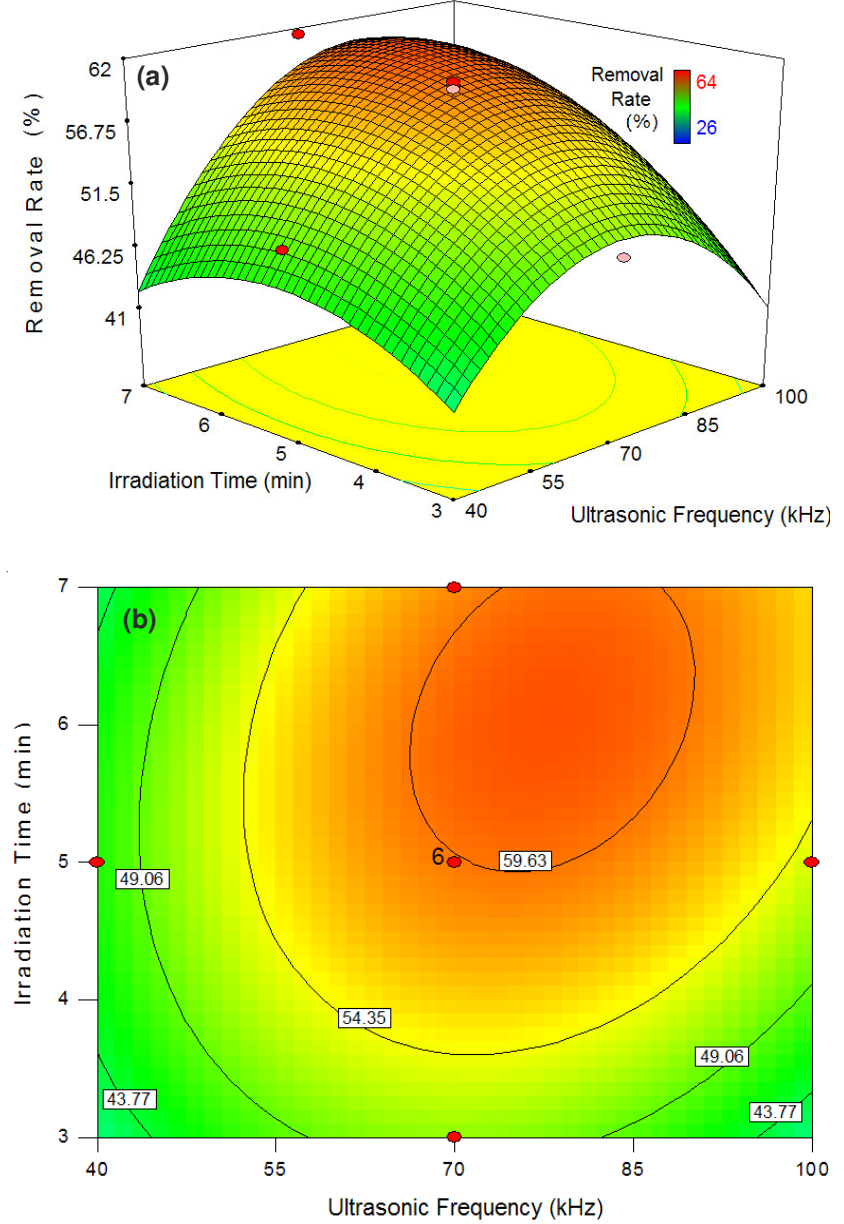

Fig. 6. Interactive effect of ultrasound frequency and irradiation time (a) $3 \mathrm{D}$ surface (b) 2D

With the irradiation time increase, the removal rate of chlorophyll- $a$ also increased, but the increasing trend has been slowing. It is similar to the effect of ultrasonic frequency for the removal rate of chlorophyll-a. This may be due to the harmonics, which caused by the cavitation derived the vibration of a single cell. Meanwhile, the collisions between algal cells in the algae fluid is also be exacerbated, which make the algae cell damage and death, finally lead to the decreasing chlorophyll-a content. With the ultrasonic irradiation time increase, the number of algae cell decreased. While the algal density decreased, the collision chances of algae cells with each other decreased. This is the reason for the removals rate of chlorophyll-a increased slowly.

The interaction between ultrasound frequency and irradiation time manifested in that, the closer the irradiation time is to the optimal experimental conditions $(7 \mathrm{~min})$ and the closer the ultrasound frequency is to the optimal experimental conditions $(77 \mathrm{kHz})$, the greater the removal rate is.

Because of the interaction, there is an optimal area of the removal rate, which is the semi-elliptical area shown in the figure. Where the frequency is about $60 \mathrm{kHz}-90 \mathrm{kHz}$ and irradiation time is about $4.5 \mathrm{~min}-7.0 \mathrm{~min}$. In this area, the removal rate is all above $63.12 \%$.

The effect of ultrasound power and irradiation time to the removal rate of chlorophyll- $a$ and the interaction between the two factors are shown in Fig. 7.
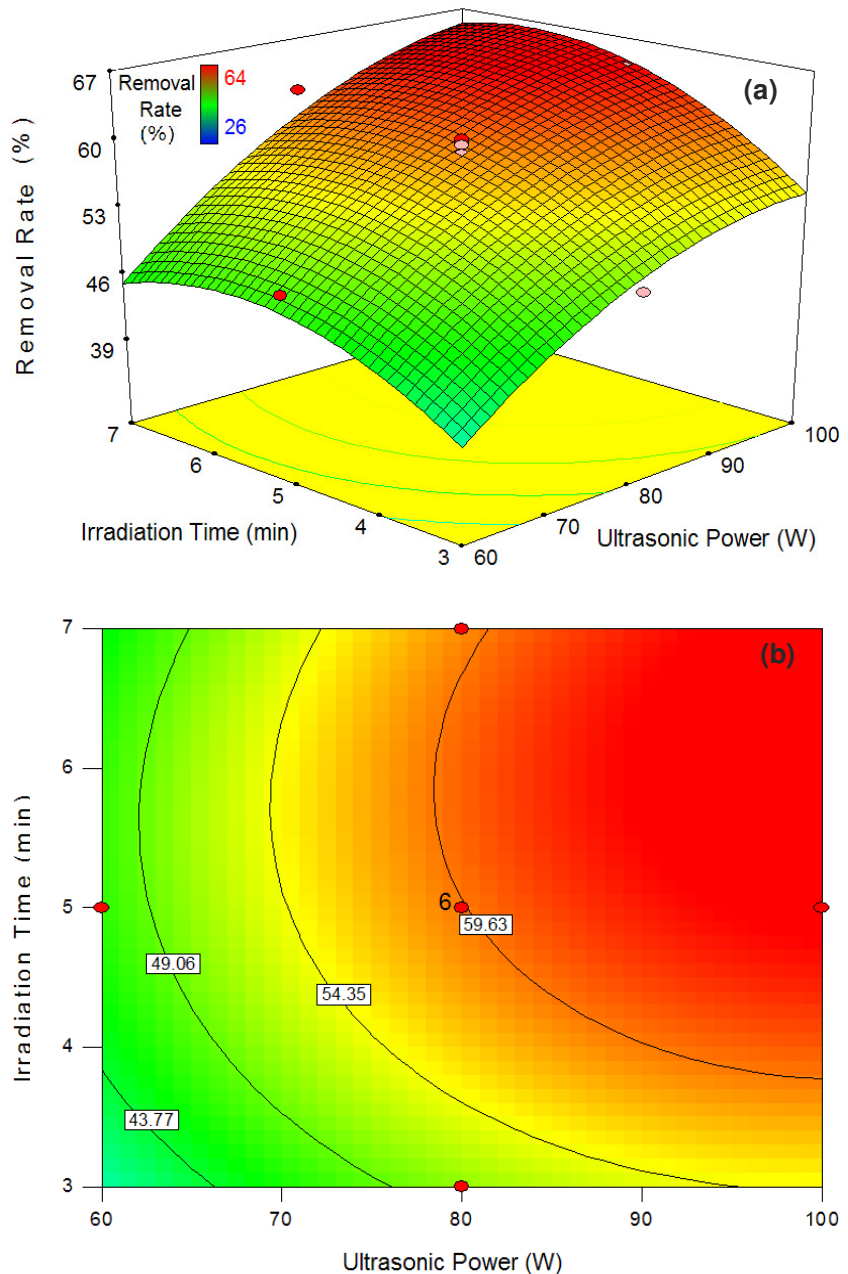

Fig. 7. Interactive effect of ultrasound power and irradiation time (a) 3D surface (b) 2D

The interaction between ultrasound power and irradiation time is not very obvious. So, the response surface is close to flat. But, there are still optimal area of the removal rate, which is the semi-elliptical area shown in the figure, where the power is about $210 \mathrm{~W}$ to $100 \mathrm{~W}$ and irradiation time is about $4.5 \mathrm{~min}$ to $7.0 \mathrm{~min}$. In this area, the removal rate is more than $62.25 \%$.

In summary, this experiment indicated that, there are significant interactions among the three factors of ultrasonic frequency, ultrasonic power and irradiation time. Correspond to the maximum value of the removal rate, both of the ultrasonic frequency and the irradiation time has an optimal value.

Regression equation can be written as eqn. (3):

$$
\mathrm{Y}=\mathrm{a}+\mathrm{X}^{\mathrm{T}} \mathrm{b}+\mathrm{X}^{\mathrm{T}} \mathrm{cX}
$$

In which:

$$
\mathrm{X}=\left[\mathrm{X}_{1}, \mathrm{X}_{2}, \mathrm{X}_{3}\right]^{\mathrm{T}}
$$

Firstly,

$$
\frac{\partial Y}{\partial X}=0
$$

Equal to:

$$
\frac{\partial Y}{\partial X}=\left[\frac{\partial Y}{\partial X_{1}}, \frac{\partial Y}{\partial X 2}, \frac{\partial Y}{\partial X 3}\right]=0
$$

Among them, the limit condition is $\mathrm{X}_{2} £ 100$ 
After implementing, the eqn. (7) is

$\left[\begin{array}{ccc}0.022 & 1.304 \times 10^{-3} & -0.057 \\ 1.304 \times 10^{-3} & 18.202 \times 10^{-3} & -0.033 \\ 0.057 & 0.033 & -2.360\end{array}\right] \bullet\left[\begin{array}{l}X_{1} \\ X_{2} \\ X_{3}\end{array}\right]=\left[\begin{array}{c}1.425 \\ 1.826 \\ -7.213\end{array}\right]$

The solution is: $X_{1}=77, X_{2}=100, X_{3}=7.0$

That is to say, the optimal condition for the Chlorella pyrenoidosa removal is ultrasound frequency of $77 \mathrm{kHz}$, ultrasonic power of $100 \mathrm{~W}$, irradiation time of $7 \mathrm{~min}$.

Verification of the model: In order to verify the prediction results, select the ultrasonic frequency as $77 \mathrm{kHz}$, ultrasonic power as $100 \mathrm{~W}$, irradiation time as $7 \mathrm{~min}$ to be the reaction conditions. Taking three groups and a control group to test, the average of removal rate as $64.4 \%$ was received. Comparing with the result of verification experiments using the same conditions, the error is $2.87 \%$, between which the predicted values are of good fit. Therefore, the model has some practical value for the accurate analysis and forecasting of ultrasonic parameters of Chlorella pyrenoidosa removal.

\section{Conclusion}

According to the single factor analysis, algae removal effect as ultrasonic frequency increases first and then decrease, in the optimal values of $80 \mathrm{kHz}$. Improvement of ultrasonic power can improve the effect of removal. After 5 min's irradiation, increasing irradiation time makes no significant impact.

Using CCD model of response surface method for optimization in ultrasonic frequency, power and irradiation time of the experiment, the quadratic polynomial regression equation established in response to removal rate of chlorophyll- $a$ has a high degree of distinctiveness $(\mathrm{P}<0.0001), \mathrm{R}^{2}=$ 0.9987 and loss of the proposed items is not significant. Regression equation was well fit with the actual situation. Ultrasonic frequency, ultrasonic power and irradiation time and the interaction of the three had significant impacts on treatment effect.

When use the ultrasound to remove the Chlorella pyrenoidosa in the logarithmic phase, the optimal parameters are ultrasonic frequency of $77 \mathrm{kHz}$, ultrasonic power of 100 $\mathrm{W}$, irradiation time of $7 \mathrm{~min}$.

\section{ACKNOWLEDGEMENTS}

This work was financially supported by the National Key Technology R \& D Program from Chinese National Science and Technology (No.2007BAB21B01), National Key Science and Technology Special Projects (2009ZX07315-002), Fundamental Research Funds for the Central Universities of China (No.CDJXS10 210003), the Science and Technology Tackle Key Problem in Chongqing (CSTC2010AC7081) and Fund of Chongqing University's Large-scale Equipment (2010011528).

\section{REFERENCES}

1. H.W. Hao, Y.F. Chen, M.S. Wu, J.W. Tang and Q.Y. Wu, Acta Biophys. Sinica, 101, 19 (2003) (in Chinese).

2. X.A. Liu, M. Zhan and Y.E. Ma, Chin. J. Environ. Sci., 26, 95 (2005), (in Chinese).

3. C.Y. Ahn, M.H. Park and S.H. Joung, Environ. Sci. Technol., 37, 3031 (2003).

4. J. Tang and Q. Wu, J. Appl. Phycol., 15, 37 (2003).

5. A.C.V. dos Santosa and J.C. Masini, Microchem. J., 93, 110 (2009).

6. P.L. Zhang and S.Y. Lin, Acta Phys. Sinica, 58, 7797 (2009) (In Chinese).

7. Q. Zhang, X.H. Zou and J.C. Cheng, Acta Phys. Sinica, 56, 6476 (2006), (in Chinese).

8. J.W. Tang and Q.Y. Wu, H.W. Hao, Y.F. Chen and M.S. Wu, Colloid. Surf. B, 36, 115 (2004).

9. H.W. Hao and M.S. Wu, Y.F. Chen, J.W. Tang and Q.Y. Wu, Colloid. Surf. B, 33, 151 (2004).

10. Y. Yang and F.D. Zong, Chin. J. Theoret. Appl. Mech., 41, 9 (2009) (in Chinese).

11. G.M. Zhang and P.Y. Zhang, B. Wang and H. Liu, Ultrason. Sonochem., 13, 446 (2006). 